Relations industrielles

Industrial Relations

\title{
Human Relations in Business, bv Keith Davis, N.Y., McGraw-Hill, 1957, pp. 547.
}

\section{Louis-Marie Tremblay}

Volume 13, numéro 1, janvier 1958

URI : https://id.erudit.org/iderudit/1022483ar

DOI : https://doi.org/10.7202/1022483ar

Aller au sommaire du numéro

Éditeur(s)

Département des relations industrielles de l’Université Laval

ISSN

0034-379X (imprimé)

1703-8138 (numérique)

Découvrir la revue

Citer ce compte rendu

Tremblay, L.-M. (1958). Compte rendu de [Human Relations in Business, bv

Keith Davis, N.Y., McGraw-Hill, 1957, pp. 547.] Relations industrielles / Industrial

Relations, 13(1), 115-115. https://doi.org/10.7202/1022483ar

Tous droits réservés (C Département des relations industrielles de l’Université Laval, 1958
Ce document est protégé par la loi sur le droit d'auteur. L’utilisation des services d'Érudit (y compris la reproduction) est assujettie à sa politique d'utilisation que vous pouvez consulter en ligne.

https://apropos.erudit.org/fr/usagers/politique-dutilisation/ 
Human Relations in Business, by Keith Davis, N.Y., McGraw-Hill, 1957, pp. 547.

Dans sa préface, l'auteur écrit: \&I have tried to present a book with content and substance rather than elementary platitudes and wheezes ». L'objectif est parfaitement atteint, car Human Relations in Business est du meilleur calibre en son genre. En plus d'ètre récent et à point, il est d'une clarté et d'une cohésion supérieures à la majorité des écrits sur le sujet. Les nombreux aspects des relations humaines sont analysés comme appartenant à un tout, et les différents points de vue sont exprimés avec objectivité, non dans un amas confus de matière mal digérée qui étourdit le lecteur, mais dans une discussion bien intégrée des fondements des relations humaines dans l'industrie. Le tout, abondamment supporté par des dessins, cartes, tableaux, graphiques et diagrammes qui illustrent les énoncés, par ane bibliographie complémentaire à la fin de chaque chapitre et, par l'étude d'une quinzaine de cas-problèmes choisis dans le monde industriel.

L'énumération de certains des points majeurs couverts donnera une idée de l'ampleur de la matière: L'entraînement, le «role playing », la participation dynamique des groupes, l'administration des salaires et des taux à la pièce, les méthodes de travail, «employee counseling », la négociation collective, le règlement des griefs et le moral.

Davis définit la nature des relations humaines, puis situe le problème au sein de l'organisation d'une entreprise. Dans sa partie maîtresse, il montre comment la direction peut améliorer ses relations avec ses employés à travers toutes les activités du personnel. Il ne demeure pas dans l'abstrait, mais aborde les problèmes avec l'optique que l'expérience a enseignée aux administrateurs. Il discute à la fois les méthodes directes et indirectes de promouvoir les relations de travail avec leurs faiblesses, leurs avantages et les difficultés qu'elles peuvent soulever.

L'auteur pose comme principe que les relations humaines sont un art plutôt qu'une science. Il aborde ainsi les rapports humains avec une conception humanitaire et sociale qui veut que les gens soient considérés comme des êtres humains. Keith Davis est un homme d'une grande compétence. Il est expert conseil pour de nombreuses entreprises et professeur en administration au School of Business, Indiana University. Ce volume est le fruit de vingt années d'expériences et de recherches dans l'industrie et l'enseignement. Il sera utile pour la formation du personnel de maîtrise, pour l'éducation des adultes et pour les écoles d'administration et gestion des entreprises.

\section{L.-M. Tremblay}

\section{Urban Land Use Planning. By F. Stuart} Chapin Jr. New York: Harper \& Brothers, 1957. XV \& 397 p. $\$ 8.00$ ( $\$ 6.00$ text book).

Les urbanistes affirment de plus en plus leur souci d'appuyer leur discipline, essentiellement tournée vers l'application, sur l'investigation scientifique, rigoureuse, de la réalité urbaine. A cette exigence des praticiens, le professeur Chapin tente, dans son ouvrage, d'apporter certains éléments de réponse. Son effort s'applique à un aspect fondamental de la planification urbaine: l'aménagement du cadre spatial de la ville.

Aux Etats-Unis particulièrement, on a consacré de nombreuses études à la recherche des mécanismes à travers lesquels se constitue le paysage urbain. Chapin se propose, dans la première partie de son ouvrage, de présenter une synthèse de ces travaux. C'est ainsi qu'il analyse les tentatives théoriques de Burgess, McKenzie, Hoyt, Harris et Ullman, Firey, etc., où l'on insiste tantôt sur les facteurs d'ordre économique, tantôt sur les facteurs d'ordre culturel. Mais cette démarche n'est, pour l'auteur, qu'un point de départ.

Son ambition est de contribuer à «l'élaboration d'un modèle théorique susceptible de guider le travail de l'urbaniste» (p. 5). Il est exact que l'urbaniste doit appuyer ses projets sur l'analyse scientifique de la réalité qu'il a dessein d'ordonner, que ses plans reflètent souvent davantage des conceptions personnelles que les voeux des citoyens eux-mêmes (p. 71). Il y a lieu toutefois, à notre sens, d'apporter quel- 